\title{
Level of Knowledge about Tuberculosis among Type 2 Diabetes Mellitus Patients at the Endocrine Clinic Dr. Hasan Sadikin General Hospital Bandung
}

\author{
Ulfah Dwi Febriani, ${ }^{1}$ Rovina Ruslami, ${ }^{2}$ Bachti Alisjahbana ${ }^{3}$ \\ ${ }^{1}$ Faculty of Medicine Universitas Padjadjaran, ${ }^{2}$ Department of Pharmacology and Therapy Faculty \\ of Medicine Universitas Padjadjaran, ${ }^{3}$ Department of Internal Medicine Faculty of Medicine \\ Universitas Padjadjaran/Dr. Hasan Sadikin General Hospital Bandung
}

\begin{abstract}
Background: Diabetes Mellitus (DM) is one of the risk factors for tuberculosis (TB). Knowledge of TB is essential in prevention control for the person at risk. This study aimed to describe the level of knowledge about TB among DM patients.

Methods: A cross sectional study was performed involving 72 adult DM patients at the Endocrine Clinic, Dr. Hasan Sadikin General Hospital Bandung. The subjects were interviewed using a standardized questionnaire including socio-demographic information and knowledge about TB: manifestation of TB, transmission, treatment, DM-TB co-infections, and status acquiring TB information in the last 12 months. Knowledge was categorized as high, moderate and low if total scores were $>75,56-75$ and $<56$ respectively. Data were presented descriptively as percentage and mean (SD) after testing for the normality of distribution.

Results: The mean of age of subjects was 56.6 years, and 55\% were female. Most were unemployed (72.2\%), had an education background lower than high school (75\%), and lived in Bandung (91.7\%). The mean score of knowledge was 54.4. Proportion of subjects based on the level of knowledge which is high, moderate and low, were $29.2 \%, 26.4 \%$, and $44.4 \%$ respectively.

Conclusions: The level of knowledge about TB among Type 2 DM patients at the Endocrine Clinic Dr. Hasan Sadikin General Hospital Bandung was low. TB education program among DM patients needs to be improved.
\end{abstract}

Keywords: Diabetes Mellitus, knowledge, tuberculosis

\section{Introduction}

Diabetes Mellitus (DM) is one of the risk factors of Tuberculosis (TB). Increasing DM prevalence is associated with increasing prevalence of TB cases $^{1,2}$ Increasing DM prevalence occurred significantly in developing countries, including Indonesia, where TB is endemic. ${ }^{3,4}$ In 2010, 285 million adults (aged 20-79 years) in the world were affected by DM and the prevalence was $6.4 \%$. The prevalence will increase to $7.7 \%$, affecting 439 million adult patients in 2030. In developing countries, there will be $69 \%$ increase in DM patients in adults. ${ }^{3}$ The DM patients have two to five times risk toward TB infection compared to non-DM patients. ${ }^{5}$ Increasing DM prevalence is a serious precaution in TB infection control. ${ }^{6}$

Awareness and knowledge of $\mathrm{TB}$ is essential in TB control strategies. Patients who have satisfactory knowledge of TB are less likely to be delayed in seeking TB care. ${ }^{7}$ Health education program in TB control should increase knowledge about the clinical manifestation, mode of transmission, role of sputum examination, curability of the disease and the availability of diagnostic and TB treatment services in health facilities. Awareness about the clinical manifestation of TB, transmission of TB, and misconception may affect population health-care seeking behavior. $^{8}$

Studies about level of knowledge about TB among Bandung population are rarely performed. This study was conducted to describe the level of knowledge about TB among DM patients at the Endocrine Clinic, Dr. Hasan Sadikin General Hospital, Bandung.

\section{Methods}

A cross sectional study was conducted at the

Correspondence: Ulfah Dwi Febriani, Faculty of Medicine, Universitas Padjadjaran, Jalan Raya Bandung-Sumedang Km.21, Jatinangor, Sumedang, Indonesia, Email: ulfahdwifebriani@gmail.com 
Ulfah Dwi Febriani, Rovina Ruslami, Bachti Alisjahbana: Level of Knowledge about Tuberculosis among Type 513 2 Diabetes Mellitus Patients at the Endocrine Clinic Dr. Hasan Sadikin General Hospital Bandung

Endocrine Clinic, Dr. Hasan Sadikin General Hospital Bandung between SeptemberNovember 2015, after obtaining approval from the ethical committee of Dr. Hasan Sadikin General Hospital Bandung. The subjects were adult type 2 DM patients (aged 18 years or above) treated at the Endocrine Clinic Dr. Hasan Sadikin General Hospital Bandung between September-November 2015 , and voluntarily joined the study after a written informed consent. Diabetic patients who had received TB treatment or were in the TB treatment period were excluded from the study. The minimal number of subject was 49 .

Socio-demographics data and knowledge about TB were obtained by direct interview using a standardized questionnaire consisting of 12 questions. The questionnaire was formed using the frame from the questionnaire of the American International Health Alliance. ${ }^{9}$ Topics of the questions were clinical manifestation of TB, transmission of TB, treatment of TB, TB-DM co-infection, and status of getting information about TB in the last 12 months. Furthermore, the questionnaire was tested for its validity and reliability. The reliability score (Chronbach's alpha) was 0.962 .

The score was 1 for a correct and 0 for a wrong answer. For multiple-answer questions such as clinical manifestation and transmission of TB, subjects may answer more than one answer, and the answer was correct if subjects mentioned minimal one correct answer. The final score was categorized into high, moderate and low if the total score was $>75,56-75$ and $<56$ respectively according to Arikunto's theory (2006). Data were presented descriptively as percentage (\%) and central tendency (mean + SD) after testing for normality of distribution using KolmogorovSmirnov.

\section{Results}

Half of the subjects were male, and the mean age was 56.6 years. The minimum and the maximum age was 31 and 82 . Three-quarters of them were graduated from high school and lower. Most were unemployed while 9 out of 10 subjects lived in Bandung (Table 1).

The mean score of knowledge about TB among DM patients was 54.4; per category it was considered as low. The lowest and highest score was 0 and 100 . Almost half of the subjects were with low level of knowledge about TB (Figure 1).

There was similarity in age among the three groups (high, moderate, and low level
Table 1 Characteristics of Subjects

\begin{tabular}{lc}
\hline \multicolumn{1}{c}{ Characteristic } & n=72 (\%) \\
\hline Gender, $\mathrm{n}(\%)$ & $32(44.4)$ \\
Male & $40(55.6)$ \\
Female & $56.6 \pm 9.7$ \\
Age, mean \pm SD & \\
Educational level, n (\%) & $16(22.2)$ \\
Primary School & $14(19.5)$ \\
Junior High School & $24(33.3)$ \\
Senior High School & $6(8.3)$ \\
Vocational training & $12(16.7)$ \\
University & \\
Employment, n (\%) & $20(27.8)$ \\
Employed & $52(72.2)$ \\
Unemployed & \\
Residence, n (\%) & $66(91.7)$ \\
Bandung & $6(8.3)$ \\
Outside Bandung &
\end{tabular}

of knowledge about TB). In the group of DM patients with good level of knowledge of $\mathrm{TB}$, there were more males than females, meanwhile in other groups (moderate and low) they were dominated by females (around $60 \%$ ). Based on educational level, subjects with moderate and low level of knowledge were dominated by groups of high school graduates and below. There were more unemployed subjects in the group of low level of knowledge about TB

This study elaborated the detail of knowledge about TB by inquiring about 5 different aspects: knowledge about clinical manifestation of TB, transmission of TB, treatment of TB, TB-DM information, and exposure to $\mathrm{TB}$ information in the last 12 months. Moreover, more than half of the subjects knew about the clinical manifestation of TB and transmission of TB. Three-quarter of the subjects were aware that TB is curable; half of them knew that the treatment of TB will be 6 months, but only one out of 10 of them recognized rifampicin as an anti-TB drug (Table 3).

Regarding TB DM co- infection, half of the subjects knew that persons with low immunity were vulnerable to TB, but only one out of three subjects knew that people with DM were vulnerable to TB. Knowledge about routine 


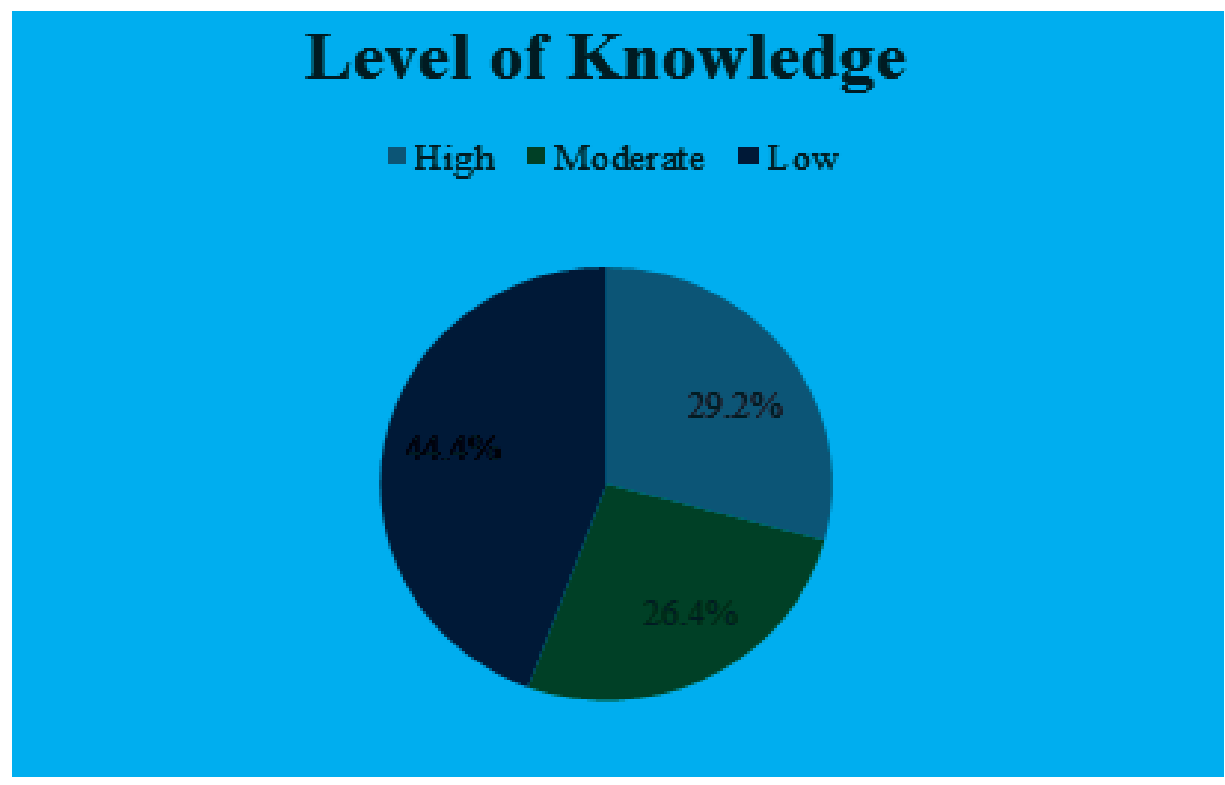

Figure 1 Proportion of Subjects based on the Level of Knowledge about TB

control and DM treatment could reduce risk of getting infected with TB was known by only half of the subjects.

Only one-third of the subjects got information about TB in the last 12 months. Almost $70 \%$ of subjects did not obtain information about TB in the last 12 months (Table 3).

Table 2 Characteristics of Subjects and Level of Knowledge about Tuberculosis

\begin{tabular}{lccc}
\hline \multirow{2}{*}{ Characteristics } & \multicolumn{3}{c}{ Level of Knowledge about Tuberculosis } \\
\cline { 2 - 4 } & $\begin{array}{c}\text { High } \\
\text { n (\%) }\end{array}$ & $\begin{array}{c}\text { Moderate } \\
\text { n (\%) }\end{array}$ & $\begin{array}{c}\text { Low } \\
\text { n (\%) }\end{array}$ \\
\hline Gender & & & \\
Male & $13(61.9)$ & $8(42.1)$ & $11(34.4)$ \\
Female & $8(38.1)$ & $11(57.9)$ & $21(65.6)$ \\
Age, mean \pm SD & $52.7 \pm 10.3$ & $58.6 \pm 9.5$ & $57.9 \pm 8.9$ \\
Educational level & & & \\
Primary School & $1(4.8)$ & $4(21.1)$ & $11(34.4)$ \\
Junior High School & $3(14.3)$ & $3(15.8)$ & $8(25)$ \\
Senior High School & $7(33.3)$ & $6(31.6)$ & $11(34.4)$ \\
Vocational training & $1(4.8)$ & $4(21.1)$ & $1(3.1)$ \\
University & $9(42.8)$ & $2(10.5)$ & $1(3.1)$ \\
Employment & & & $8(25)$ \\
Employed & $8(38.1)$ & $4(21.1)$ & $24(75)$ \\
Unemployed & $13(61.9)$ & $15(78.9)$ & \\
Residence & & & $30(93.8)$ \\
Bandung & $20(95.2)$ & $16(84.2)$ & $2(6.3)$ \\
Outside Bandung & $1(4.8)$ & $3(15.8)$ & \\
\hline
\end{tabular}


Table 3 Satisfaction Distribution Based on Dimensions of Service Quality

\begin{tabular}{lcc}
\hline \multicolumn{1}{c}{ Questions } & \multicolumn{2}{c}{ Answer } \\
\cline { 2 - 3 } & $\begin{array}{c}\text { Correct } \\
\mathbf{n}(\%)\end{array}$ & $\begin{array}{c}\text { Incorrect } \\
\mathbf{n}(\%)\end{array}$ \\
\hline Clinical Manifestation of TB & & \\
$\quad$ One main manifestation of TB & $41(56.9)$ & \\
Transmission of TB & & \\
TB is infectious & $51(70.8)$ & $21(29.2)$ \\
TB is transmitted by droplet/sputum & $48(66.7)$ & $24(33.3)$ \\
Treatment of TB & & \\
$\quad$ TB is curable & $53(73.7)$ & $19(26.3)$ \\
$\quad$ Treatment of TB is minimum 6 months & $33(45.8)$ & $39(54.2)$ \\
$\quad$ Rifampicin as anti-TB drug & $9(12.5)$ & $63(87.5)$ \\
$\quad$ Time to stop TB treatment & $26(36.1)$ & $46(63.9)$ \\
TB DM co-infection & & \\
Person with low immunity level is vulnerable to TB & $41(56.9)$ & $31(43.1)$ \\
Control and DM treatment reduces risk of getting TB & $37(51.4)$ & $35(48.6)$ \\
$\quad$ DM patients is vulnerable to TB & $27(37.5)$ & $45(62.5)$ \\
TB patients with DM is more difficult to recover & $26(36.1)$ & $46(63.9)$ \\
Acquiring TB information in last 12 months & $22(30.6)$ & $50(69.4)$ \\
\hline
\end{tabular}

\section{Discussion}

This study found that DM patients' level of knowledge about TB was limited. The mean score of knowledge about TB among DM patients was 54.4; per category it was considered as low. The proportion of subjects based on the level of knowledge about TB which was high, moderate and low, were $29.2 \%, 26.4 \%$, and $44.4 \%$ respectively. The fact that only one-third of subjects obtained information about TB in last 12 months, might explain the low level of knowledge about TB in this study. This level of knowledge was comparable to 59\% newly-diagnosed pulmonary TB patients in Nigeria ${ }^{10}$, and $64 \%$ in Sudan ${ }^{11}$ that have unsatisfactory knowledge of TB. Similar to the study in Tanzania ${ }^{12}$, this study showed that the majority (70\%) of subjects were with unsatisfactory knowledge of TB. ${ }^{12}$ The higher level of knowledge of the Nigeria $^{10}$ study could be explained by the higher level of education among the subjects. The correlation further explained in the Tanzania study, apparently was not explored in this study.

Questions about the clinical manifestation of TB and transmission of TB were answered correctly by more than half of the subjects. Less than half of the subjects were aware about the duration of treatment, and only onetenth of them knew that rifampicin as an antiTB drug. Furthermore, only one-third of them knew about the time to stop TB treatment. Similar to this findings, subjects of previous study in Tanzania ${ }^{12}$ also responded poorly to questions concerning general management of TB including duration of treatment and drug side effects.

Regarding the knowledge of TB-DM coinfection, more than half subjects did not know that DM patients were vulnerable to TB. It is contrary to the fact that DM patients have more risk toward TB infection compared to non-DM patients. ${ }^{5} \mathrm{~A}$ research in Indonesia ${ }^{6}$ found a strong association between DM and TB in young and non-obese subjects and it was supported by another study in Korea. ${ }^{13}$ Almost two-third of DM patients in this study was unable to correctly answer the question that TB patients with DM are more difficult to recover than TB patients without DM. In fact, DM has a negative effect on TB treatment and is associated with lower performance status. 14,15

Furthermore, knowledge about the clinical 
manifestation, mode of transmission, role of sputum examination, curability of the disease and the availability of diagnostic and TB treatment services in health facility are associated with health seeking behavior.8 Patients with lack of knowledge about TB were more likely to be delayed in seeking patients care. ${ }^{7,10}$ Indeed, early diagnosis and effective treatment are the best way to control TB infection.

This study found that only one-third of DM patients were being exposed to information about TB in the last 12 months. Besides, the TB education program among DM patients should be intensified, especially in Indonesia because Indonesia is in the top ten for countries in numbers of people with DM. ${ }^{3,16}$ The TB control program should include educational intervention using alternative media with suitable modification to reach all sectors. ${ }^{17}$ Effectiveness of the TB education program was proven by a study in India ${ }^{17}$ which explained the information, education and communication (IEC) campaign about TB has positive impacts on increasing awareness and improving selfreporting of the general population.

This study has several limitations. The subjects of this study were taken only at the Endocrine Clinic of Dr. Hasan Sadikin General Hospital Bandung and were not compared to any other place. The phenomenon of differences between the study subjects and general population cannot be captured properly. This study was conducted without considering about factors associating the level of knowledge and the association between knowledge and attitude. Further studies are needed to compare the knowledge of TB among diabetic patients treated in hospital and primary health care, to analyze the factors associated with the level of knowledge, and to find the association between knowledge and attitude.

In conclusion, the level of knowledge about TB among DM patients at the Endocrine Clinic of Dr. Hasan Sadikin General Hospital Bandung is low. Almost half of the diabetic patients are with low level of knowledge about TB, one third is high and a quarter of them was moderate. The TB control programs for educating DM patients should be improved.

\section{References}

1. Leung CC, Lam TH, Chan WM, Yew WW, Ho KS, Leung GM, et al. Diabetic control and risk of tuberculosis: a cohort study. Am J Epidemiol. 2008;167(12):1486-94.
2. Stevenson CR, Forouhi NG, Roglic G, Williams BG, Lauer JA, Dye C, et al. Diabetes and tuberculosis: the impact of the diabetes epidemic on tuberculosis incidence. BMC public health. 2007;7(1):234-41.

3. Shaw JE, Sicree RA, Zimmet PZ. Global estimates of the prevalence of diabetes for 2010 and 2030. Diabetes Res Clin Pract. 2010;87(1):4-14.

4. WHO. Global tuberculosis report 2014. Geneva: World Health Organization; 2014.

5. Alisjahbana B, Crevel Rv, Sahiratmaja E, Heijer Md, Maya A, Istriana E, et al. Diabetes mellitus is strongly associated with tuberculosis in Indonesia. Int J Tuberc Lung Dis. 2006;10(6):696-700.

6. Mondal M, Nazrul HM, Chowdhury M, Howard J. Socio-demographic factors affecting knowledge level of Tuberculosis patients in Rajshahi City, Bangladesh. Afr Health Sci. 2015;14(4):855-65.

7. Suganthi P, Chadha V, Ahmed J, Umadevi G, Kumar P, Srivastava R, et al. Health seeking and knowledge about tuberculosis among persons with pulmonary symptoms and tuberculosis cases in Bangalore slums. Int J Tuberc Lung Dis. 2008;12(11):1268-73.

8. American International Health Alliance. Strengthening tuberculosis control in Moldova. Washington DC: USAID; 2007.

9. Biya O, Gidado S, Abraham A, Waziri N, Nguku P, Nsubuga P, et al. Knowledge, careseeking behavior, and factors associated with patient delay among newly-diagnosed pulmonary tuberculosis patients, Federal Capital Territory, Nigeria, 2010. Pan Afr Med J. 2014;18(Suppl 1):6-10.

10. Mohammed A, Yousif M, Ottoa P. Knowledge of tuberculosis: a survey among tuberculosis patients in Omdurman, Sudan. Sudanese J Public Health. 2007;2(1):22-8.

11. Wandwalo E, Mørkve O. Knowledge of disease and treatment among tuberculosis patients in Mwanza, Tanzania. Int J of Tuberc Lung Dis. 2000;4(11):1041-6.

12. Koo BK. Diabetes mellitus and tuberculosis. Diabetes Metab J. 2013;37(4):249-51.

13. Alisjahbana B, Sahiratmadja E, Nelwan EJ, Purwa AM, Ahmad Y, Ottenhoff TH, et al. The effect of type 2 diabetes mellitus on the presentation and treatment response of pulmonary tuberculosis. Clin Infect Dis. 2007;45(4):428-35.

14. Baker MA, Harries AD, Jeon CY, Hart JE, Kapur A, Lönnroth K, et al. The impact of diabetes on tuberculosis treatment outcomes: a systematic review. BMC Med. 2011;9(1):81-95. 
15. Wild S, Roglic G, Green A, Sicree R, King H. Global prevalence of diabetes estimates for the year 2000 and projections for 2030. Diabetes Care. 2004;27(5):1047-53.

16. Sreeramareddy CT, Kumar HH, Arokiasamy JT. Prevalence of self-reported tuberculosis, knowledge about tuberculosis transmission and its determinants among adults in India: results from a nation-wide cross-sectional household survey. BMC Infect Dis. 2013;13(1):16-24.

17. Sharma N, Taneja D, Pagare D, Saha R, Vashist R, Ingle G. The impact of an IEC campaign on tuberculosis awareness and health seeking behaviour in Delhi, India. Int J Tuberc Lung Dis. 2005;9(11):125965. 